\title{
The Evolving Regulatory Role of the U.S. Office of Management and Budget
}

\author{
John D. Graham*
}

\section{Introduction}

On New Year's Eve of 2001, after the disputed Florida recount, I received a call from the Bush-Cheney transition team. They asked me to consider a senior regulatory post in the Office of Management and Budget (OMB), the largest unit within the Executive Office of the President.

The call was a pleasant surprise since I had not been involved in the Bush-Cheney campaign. In fact, I answered gingerly a question about why I made a financial contribution to Elizabeth Dole's short-lived 2000 presidential campaign.

Having taught benefit-cost analysis for seventeen years at the Harvard School of Public Health, the opportunity to practice what I was preaching was intriguing. And my own scholarship on regulation of health risks had called for a more rigorous approach to selecting regulatory priorities, weighing risks, and devising cost-effective solutions (Graham and Wiener 1995; Graham 1997). Thus, I accepted the offer to serve with hopes of advancing the practice of benefit-cost analysis in regulatory policy making.

After going through a meticulous FBI background check, I was nominated in March 2001 to be the president's "regulatory czar" — the administrator of the OMB's Office of Information and Regulatory Affairs (OIRA).

The Senate confirmation process was my introduction to hardball politics in Washington, DC. A coalition of liberal activists opposed my nomination with provocative rhetoric, but their allegations were effectively countered in the confirmation process (U.S. Congress 2001). I was both encouraged and humbled when so many of my academic colleagues, both Democrats and Republicans, voiced support for my nomination. In July 2001, I was confirmed by the Senate and went to work leading fifty career policy analysts at the OIRA.

\footnotetext{
*Pardee RAND Graduate School of Policy Analysis, RAND Corporation, 1776 Main Street, P.O. Box 2138, Santa Monica, California, 90407-2138. E-mail: john_graham@prgs.edu

The author appreciates helpful comments on an earlier draft from Diana Epstein, Art Fraas, Jennifer Graham, Sue Graham, Jay Griffin, Robert Hahn, James Hammitt, Ryan Keefe, Debra Knopman, John Morrall, Paul Noe, Yuyan Shi, Elizabeth Vandersarl, Jonathan Wiener, an anonymous referee, and the journal's managing editor. Errors and opinions are the author's responsibility.
}

Review of Environmental Economics and Policy, volume 1, issue 2, summer 2007, pp. 171-191 doi: 10.1093/reep/rem013

(C) The Author 2007. Published by Oxford University Press on behalf of the Association of Environmental and Resource Economists. All rights reserved. For permissions, please email: journals.permissions@oxfordjournals.org 
The OIRA's role in federal regulation has been controversial. Since the early Reagan years, critics have argued that benefit-cost analysis is used by the OMB as a one-sided tool of deregulation to advance the interests of business. A variety of regulatory scholars and proregulation activists have raised concerns about the role of the OIRA, especially as applied to public health, safety, and environmental issues (Andrews 1984; Morrison 1986; Percival 1991; McGarity 1998). Some argue that health protection is an absolute right, even though it is difficult to base such a claim on modern philosophical theories (Schroeder 1986). They also fear a transfer of power from the regulators to the $\mathrm{OMB}$, since the civil servants working at the mission-oriented agencies tend to be more zealous about regulation than the policy analysts at the OMB (McGarity 1991; Moe and Wilson 1994).

As I entered a probusiness Republican administration, I expected that my office would work to stop bad rules and find less costly ways for regulators to achieve worthy public objectives (e.g., environmental protection). And we did so.

My purpose in this article is to disclose a little-known fact: Benefit-cost analysis also caused the OIRA to be a proregulation advocate in the Bush administration. I support this claim by providing specific examples of how and why the OIRA became a voice-usually an effective one-for sensible proregulation initiatives that addressed risks created by business activity.

I begin with a short description of the federal regulatory process, with an emphasis on the basis for the OIRA's participation in agency rule making. I then offer four case studies that illustrate how the OIRA worked with the Department of Health and Human Services (HHS) on labeling foods for trans fat content, the Department of Transportation (DOT) on improving light-truck fuel economy, and the Environmental Protection Agency (EPA) on controlling diesel engine exhaust and reducing air pollution from coal-fired power plants. I conclude with some suggestions about how science and economics can play a stronger role in federal regulation in the years ahead.

\section{The OMB and the Regulators}

Federal regulatory agencies develop rules based on legislative authority that has been delegated to them by the U.S. Congress. Since 1981, the Executive Office of the President has insisted that all major new regulations be supported by a benefit-cost analysis, including an analysis of the potential market failure that motivates the need for rule making (Smith 1984). It is now well accepted that based on presidential executive order, the OMB has authority to oversee the regulatory activities of federal agencies to ensure that presidential policies are followed and that economic analysis is undertaken to inform regulatory policy (Kagan 2001; West 2005).

In order to bring discipline to the regulatory approval process, the OMB requires agencies to submit any significant rule making proposal to the OIRA for clearance before it is published in the Federal Register (Blumstein 2001; GAO 2003). The heart of the OMB's power, as administered by the OIRA, is to return a draft rule to an agency for further consideration (OMB 2002). An agency can overrule the OIRA only by a successful appeal to the OMB director (or the president).

The OIRA does not enforce a strict, numeric benefit-cost test. Although the OIRA tracks the numbers carefully, it also considers qualitative claims about possible benefits and costs 
as well as a variety of nonefficiency arguments (e.g., matters of fairness). For example, a civil rights rule may be proposed on philosophic grounds that have nothing to do with economic efficiency. Agencies must explain why benefits justify costs, but the justification does not have to be fully monetary. Since there is no rigorous analytic tool for weighing qualitative benefits or fairness claims, the OIRA review of regulations inevitably entails some policy judgment (OMB 2002).

The key limitation on the OIRA's authority is that the OIRA may not compel a regulator to take a position that is inconsistent with the regulator's legislative authority. If the OIRA induces an agency to make such a mistake, the resulting rule is flawed and may be overturned by a federal court. Thus, a complex interaction between economic, legal, and fairness considerations, coupled with interest-group pressures, defines the negotiations between the OIRA and the regulators (McGarity 1991; Morgenstern and Landy 1997).

In the summer of 2001, my boss, OMB director Mitch Daniels (now the governor of Indiana), explained to me his views on why the OMB should oversee the regulators. He said that just as no modern president has permitted a cabinet department to set its own budget without OMB review, no recent president has permitted federal regulators to impose offbudget expenditures - typically "unfunded mandates" on businesses or states - without review by analysts in the Executive Office of the President. Yet Daniels also stressed that the OIRA could do a good job only if it engaged in careful consideration of benefits as well as costs.

In order to demonstrate the OIRA's backbone, Daniels urged me to move quickly to return some bad or poorly reasoned rule making proposals to agencies. I signed more than twenty of these official return letters in my first year on the job (OMB 2002). That is more than the overall number of returns in eight years of the Clinton administration, but a much lower return rate than in the Reagan years (Power and Schlesinger 2002). Once the regulators realized that I was willing to exercise this power, it became far less necessary to use it. We were able to work out problems with an agency in advance, without the need for any public rebuke.

To make it easier for regulators to understand the OIRA's analytic perspective, we published a formal guidance document ("OMB Circular A-4") that outlines what the OIRA expects to see in a regulatory analysis, especially the benefit-cost evaluation. This document, which is available on the OMB's Web site, was finalized only after the OIRA made revisions to a draft document that was subjected to public comment and expert peer review by academics and other scholars on regulatory policy (OMB 2003). I turn now to the four case studies of the OIRA at work with the regulators.

\section{Labeling Foods for Trans Fat Content}

Soon after taking office, one of my senior career staff who covered HHS brought to my attention a rule making that was started in the Clinton administration but had never been finished. That was hardly a rare situation, but my economics staff insisted that this rule making was permissible under existing law, and a good idea.

The proposal, which had been drafted by the Food and Drug Administration (FDA), would have compelled food companies to include the trans fat content on the food label, just as calories and saturated fat content are disclosed. The FDA's economists argued that 
a variety of informational obstacles were preventing the market from responding to the dangers of trans fats. They believed that the new label would not only aid consumer choice but also encourage food processors to reduce the trans fat content of a variety of widely consumed foods. The FDA projected that the annual health benefits of the rule, measured in less heart disease, would far exceed the annual burdens, which included the costs of food processing modifications and labeling changes (FDA 2003).

The key scientific premise was that trans fat consumption is linked to the development of coronary heart disease. To verify this premise, I asked my staff to consult the recent medical literature and reach out to three groups: the Department of Nutrition at the Harvard School of Public Health, the International Life Sciences Institute (a scientific group affiliated with the food industry), and the Center for Science in the Public Interest (a nonprofit advocacy group). All of these consultations reinforced our conviction that the FDA's scientific premise was sound.

When the the OIRA desk officer checked with the FDA, we learned that the rule making was moving at a snail's pace, in part, because a new FDA commissioner had not yet been nominated. In order to accelerate this rule making, we developed a tool which we called the "prompt letter." It was intended to be a polite nudge - a suggestion that an agency give priority to a matter, or alternatively, explain to the OMB in a public reply letter why it should not be a priority (OMB 2002). However, prompt letters are not legally binding on agencies.

The lawyers in the White House disliked the idea. They argued that a prompt letter revealed too much about preliminary thinking inside the executive branch and might be seen as compromising the OIRA's objectivity in the subsequent review of a rule. However, Director Daniels did not find these objections convincing and gave us the go-ahead.

We issued the first the OIRA prompt letter to the FDA in the fall of 2001. FDA responded by finishing the final rule, and trans fat content is now a standard entry on food labels (FDA 2003). As a result of this rule making, grocery store shelves became filled with foods low in trans fat content and a variety of restaurants and food establishments are also taking new steps to reduce trans fat content.

From 2001 to 2006, I signed more than a dozen of these prompt letters, which are posted on the OMB's Web site (www.whitehouse/omb.eop.gov). Prompt letters were praised as an important innovation by some commentators outside the government (Hahn and Sunstein 2002). They were less popular at the regulatory agencies. With some justification, agencies asked why the OIRA did not simply convey its suggestions to them informally.

Indeed, later in my tenure at the OIRA, my staff persuaded me that we could often achieve the same result we had achieved on trans fats by simply scheduling a meeting with a regulator, where the topic might be a draft prompt letter or a draft return letter. Nonetheless, I favor public prompt letters from the OIRA because they exemplify the transparency in government that I believe will increase public trust in the OIRA (GAO 2003; Graham, Noe and Branch 2006). The public nature of the prompt letters also encourages outside groups to suggest promising topics for prompt letters to the OIRA and serves as an occasional reminder of the need for the OIRA staff to address shortages as well as excesses of regulation.

The development of the prompt letter and its application to FDA's trans fat rule may be an important event in the history of the OIRA, regardless of how many future prompt letters are issued. It reaffirmed in a public way that the OIRA's role is to advance the cause 
of "smart regulation," which sometimes will lead to more rather than less regulation (OMB 2002). Some scholars have suggested that there should be a presidential executive order to codify the OIRA's power to issue prompt letters (Hahn and Sunstein 2002; Bagley and Revesz 2006).

\section{Curbing Diesel Engine Exhaust}

In late 2000, the Clinton administration issued a flood of new regulations, including an ambitious rule under the Clean Air Act to reduce diesel exhaust from heavy-duty trucks operated on roads and highways. The goal was a 90 percent diesel exhaust reduction to be accomplished as refineries reduce the sulfur content of diesel fuel and engine suppliers add modern emission control equipment.

When President Bush took office in 2001, some analysts in the conservative think-tank community saw in the new Republican administration a potential opportunity to delay, modify, or rescind the highway diesel rule (OMB 2001). And, in fact, the new policy officials at the EPA were asked by some industry officials to reconsider the rule.

\section{Deciding Whether to Retain the Highway Diesel Rule}

The highway diesel rule was certainly costly, imposing annualized expenses of $\$ 3$ to $\$ 5$ billion per year on refineries and engine suppliers (OMB 2002). Those estimates assumed that the industry would experience a steady decline in variable costs over time as refiners learned how to implement desulphurization at a lower cost. The costs were a bitter pill for an industry that had been downsizing for years. In the 1990s, many small refineries struggled to break even.

Despite the significant costs, what impressed me about the rule was the in-depth benefits analysis prepared by the EPA. The rule was projected to prevent, each year, 8,300 premature deaths, 5,500 cases of chronic bronchitis and 361,400 asthma attacks. When the benefits were expressed in monetary units, they were roughly twenty times larger than the estimated costs (OMB 2002). Moreover, EPA scientists indicated that some of the important human health and ecological benefits were not even included in the benefit calculation because of gaps in scientific knowledge or uncertainty about how to express the benefits in monetary units (EPA 2004).

From an economic perspective, the producers, buyers, and users of diesel engines were creating a classic negative externality: the health risks to people breathing diesel exhaust were not fully considered in market transactions.

Much to the dismay of some White House staff, we decided against reopening the highway diesel rule (OMB 2001). In fact, rather than delay or rescind the rule, in 2002 the OIRA began work on a draft prompt letter calling for the EPA to undertake a similar rule making that would reduce exhaust from numerous off-road engines used in construction, agriculture, and mining.

\section{Reducing Exhaust from Off-road Engines}

When we met with the EPA informally on the draft prompt, they insisted that there was no need for a prompt because the rule making was already a priority. They were also pleased to learn about the OIRA's proregulation perspective. We therefore agreed to undertake 
an unprecedented EPA-OMB rule making collaboration, which was announced via press releases in June 2002 by both the EPA and the the OMB.

The complex rule making, which required a 90 percent reduction in diesel exhaust from off-road engines, was completed more quickly than is typical of large EPA rules (EPA 2004). The rule was costly ( $\$ 1.3$ billion per year), but the estimated ratio of monetary benefit to cost was over 20:1.

In the course of this rule making, we asked the EPA to undertake an analysis of benefits to determine how likely it was that benefits would prove to be large or small. The point of this probability analysis was to account for the key scientific uncertainties in the health and environmental sciences.

Interestingly, the analysis revealed that the benefits of the rule exceeded the costs, even when the most pessimistic assumptions were applied to the benefits assessment. This result caused us to ask whether the rule should be made even more stringent. However, a consensus emerged that requiring more than 90 percent sulfur removal raised feasibility concerns and might lead to unintended yet adverse consequences (Graham and Wiener 1995).

The EPA-OMB collaboration did lead to some controversy. We asked whether trading of emissions-control credits should be permitted between off-road and highway engines, since a broader trading regime might make both rules even more cost-effective. The OMB and EPA lawyers agreed that such trading authority might place the entire rule at legal risk, since the Clean Air Act has no express authority for such an expanded trading regime. Disruptive litigation could cause delays in implementation and lack of predictability for firms expected to make large capital investments. So we retreated to a more modest request that trading of credits be permitted among engines of different sizes within the same off-road engine family. The EPA agreed to this request.

As this rule making was nearing a conclusion in 2004, one of the more satisfying moments for me occurred when EPA officials were briefing skeptical White House staff about why the EPA was undertaking a billion-dollar regulation that was not the subject of any statutory deadline from Congress. Participants at the meeting turned to me: I explained that the rule had an impressive benefit-cost case, and the meeting did not last much longer.

\section{Enforcing Diesel Exhaust Rules}

Writing stringent rules is not useful if businesses do not believe they will be enforced. In 1999, the EPA and diesel engine suppliers reached a settlement on an enforcement action that alleged that some suppliers had installed computer software that turns off emission controls when a heavy truck is operated on the highway. As part of the settlement, the suppliers agreed to an accelerated compliance schedule for their new, cleaner engines being developed under the 2000 highway diesel rule.

As the accelerated deadline approached in October 2002, several companies informed the EPA that they might need a delay in the effective date; other companies indicated they were ready to go. The EPA made a strong case to us that delay was out of the question, and we agreed.

The following question then arose: How large should the noncompliance penalties be for a manufacturer that offers for sale a noncompliant engine? According to the applicable law, the penalty must be set to ensure that no manufacturer gains a competitive advantage from noncompliance. In addition to potential savings in research and development and 
equipment costs from noncompliance, the OIRA felt it was critical that any fuel economy gain over the long life of the noncompliant engine be included in the penalty. Thus, the OIRA staff worked closely with EPA staff to produce a rule that imposed large penalties for noncompliance, including the proper discounting of future fuel savings (EPA 2002).

As our policy leaked to the affected companies, the chief of the EPA's clean-air office and I were called to a meeting with members of Congress who were concerned about these noncompliance penalties. EPA was asked why the agency was harassing industry with regulatory fines, especially with such little notice. As the meeting progressed, it became apparent that the members intended to make the EPA the villain. I listened carefully but, without disclosing our thinking, suggested that there were much better targets than this rule for efforts to reduce the burdens of bad regulation. Once again, I was gratified that sound economic thinking prevailed, without any changes to the noncompliance penalties.

After the grilling on Capitol Hill, Director Daniels called me into his office for a briefing. I explained that we needed a policy that rewarded rather than punished innovators in the industry. Daniels offered this advice: "Get the rule out as quickly as possible. Undue delay allows lobbyists to bill more hours as they apply political pressure." That proved to be good advice, which we used on various occasions in the future.

\section{Promoting More Fuel-efficient Vehicles}

The run-up of fuel prices in 2001 underscored why the vice president's energy task force, which was devising a national energy policy for the president, was interested in ways to spur conservation of oil. The United States was becoming more heavily dependent on foreign sources of oil (EIA 2005), and the transportation sector was America's biggest source of oil consumption.

The market-failure rationales for oil conservation were a matter of dispute inside the Bush administration. Some analysts argued that the United States was such a large consumer of world oil that we could check the "monopoly" pricing power of OPEC through a concerted program to reduce U.S. oil consumption. Others argued that oil consumption was underpriced because world oil prices do not fully reflect national security concerns or the damages from carbon dioxide emissions that are implicated in global climate change. Still others speculated that consumer decisions about vehicle fuel economy reflected irrationally high discount rates on future gasoline expenses. Although there was no universal agreement as to which market imperfections were most important, there was a broad consensus that a national policy aimed at curbing U.S. oil consumption was required.

Recognizing that cars and light trucks accounted for the majority of oil use in the U.S. transportation sector, the vice president's energy task force made two key recommendations to enhance vehicle fuel economy (White House 2001). First, Congress should offer tax credits to consumers who purchase cars and light trucks with innovative fuel-saving technologies (e.g., hybrid engines). Second, the DOT should reexamine the Corporate Average Fuel Economy program (CAFE), which sets mileage rules for new vehicles, to determine whether CAFE should be reformed or replaced with a more market-based approach to oil savings. Some White House economists argued instead for higher fuel taxes or carbon taxes, but tax hikes were considered political suicide in Congress. 


\section{The Science and Politics of CAFE}

In 2001, the CAFE program was moribund. Although in 1974 Congress had granted the DOT authority to set mileage rules for cars and light trucks, in 1996 a bipartisan coalition in Congress began adding riders to DOT appropriations bills each year that froze CAFE standards at 27.5 miles per gallon (mpg) for cars and $20.7 \mathrm{mpg}$ for light trucks (SUVs, vans, and pick up trucks). As a result, the combined fuel economy of cars and light trucks was about twenty-five mpg in model year 2004, unchanged from ten years earlier (EPA 2006).

The environmentalists in Congress were arguing for large increases in CAFE standards, but they were outnumbered by members of Congress who feared that large CAFE increases would harm the economy, especially the auto industry. The dispute was less a partisan fight than a regional and interest-group struggle. Leading Democrats such as Carl Levin of Michigan and Dick Gephardt of Missouri opposed large CAFE increases; prominent Republicans such as John McCain of Arizona and Olympia Snowe of Maine favored stricter mileage rules.

A window of opportunity opened in August 2001 when a committee of the National Academy of Sciences released a major study of the CAFE program (NAS 2001). Chaired by Dr. Paul Portney of Resources for the Future, this committee concluded that reform of the CAFE standards could save more energy, reduce safety risks to motorists, and minimize compliance costs. While tighter CAFE standards for cars had saved fuel in the 1980s, NAS found that those same standards had caused adverse safety consequences among motorists due to the downsizing of cars. NAS suggested that size- or weight-based CAFE standards replace the uniform, fleet-wide mileage standards. In order to enhance economic efficiency, NAS also recommended that the separate CAFE programs for domestic cars, imported cars, and light trucks be combined into a single program and that permission be granted for manufacturers to trade CAFE compliance credits.

At about the same time, vehicle manufacturers and the United Auto Workers (UAW) union were beginning to realize what they were up against in California, where the state legislature passed a CAFE-like bill aimed at reducing carbon-dioxide emissions from vehicles sold in California. Other states in the northeast began to follow California's lead. The prospect of a proliferation of state CAFE programs was frightening to all elements of the industry. Reluctantly, industry leaders began to realize that a revitalized federal CAFE program was far better than putting California and various states in charge of national auto policy.

Inside the White House, the president's legislative affairs team was skeptical about whether any CAFE-related proposal could pass the Congress. Despite their reservations, the decision was made to allow the DOT to ask Congress to lift the freeze on CAFE standards and provide the DOT with new regulatory authority to implement the NAS suggestions.

The DOT proposal to reform CAFE went nowhere in the Congress. There was never even a vote on the House or Senate floor concerning the NAS reforms. Why? All of the stakeholders - the environmentalists, UAW, vehicle manufacturers, and consumer groups - were opposed to giving DOT this broad new authority. As one auto lobbyist told me, "The devil you know is better than the devil you don't know." Although Congress would not budge on the NAS reforms, it did lift the freeze on CAFE standards beginning with model year 2004 . 


\section{Tightening the Mileage Rules}

After this legislative debacle, I was asked by the White House to lead an interagency team charged with reforming CAFE administratively. Our charge was to implement as many of the NAS reforms as permitted under existing legal authority. In addition to the DOT, the team included the OIRA, the Department of Energy (DOE), the EPA, the Council of Economic Advisers (CEA), the Council on Environmental Quality, the vice president's office, and the White House policy offices.

We began by tightening mileage standards for light trucks under the existing CAFE framework while emphasizing the need to reform CAFE in the long run (DOT 2003). For model years 2005 through 2007, the DOT gradually increased light-truck mileage rules from $20.7 \mathrm{mpg}$ to $22.2 \mathrm{mpg}$. Although the rule was estimated to cost the industry (primarily GM and Ford) more than a billion dollars per year, the benefit-cost analysis showed that the net financial impact on consumers would be beneficial, even assuming that fuel prices stayed around $\$ 1.50$ per gallon through 2020. Although the extra $1.5 \mathrm{mpg}$ may sound small, it represents a savings of more than 4 billion gallons of fuel over the life of the affected vehicles - even accounting for the fact that some consumers drive more miles when their vehicles become more fuel efficient.

A key assumption in the DOT analysis was that both the private and external benefits of fuel savings should be counted. DOT analysts had learned that there was some low-hanging fruit in the engineering of fuel economy, in part because CAFE standards had been frozen for almost a decade and in part because, they speculated, many consumers apply irrationally large discount rates to future fuel savings. The DOT did consider the possibility that tighter mileage standards might reduce new vehicle sales, but this effect was found to be insignificant.

A breakthrough on one of the NAS recommendations occurred in 2003 when the lawyers on the interagency team discovered that the DOT already had the authority to adopt size-based CAFE standards for light trucks (but not for cars). This oddity in the way the 1974 CAFE law was written allowed us to develop stricter, size-based standards for the fastest growing and least fuel-efficient segment of the vehicle market: light trucks.

Using this reform authority, the DOT gradually tightened mpg targets for light trucks from 2008 through 2011. The long-time horizon of the rule making provided a degree of regulatory certainty for vehicle makers and the opportunity to consider more innovative compliance technologies (e.g., hybrid engines and advanced diesel engines).

The DOT projected that the CAFE rule makings covering model years 2005 to 2011 will boost overall light-truck fuel economy to $24.0 \mathrm{mpg}$ by 2011 , about 16 percent higher than the level prevailing when President Bush took office (DOT 2006). The DOT also projected that more than ten billion gallons of fuel will be saved. The benefit-cost analysis was favorable, in part because in 2005 the Energy Information Administration raised the long-term fuel-price projection for 2020 from $\$ 1.50$ per gallon to $\$ 2.10$ per gallon (EIA 2005). Since private fuel savings are counted in the DOT analysis, a higher projected fuel price causes higher benefit estimates for those technologies that manufacturers do not plan to implement voluntarily.

For the first time in the history of the CAFE program, the DOT set the stringency of the CAFE standards at the point where marginal benefits equaled marginal costs. In setting 
the mpg targets, no consideration was given to the financial condition of Ford and GM compared to Toyota and the other vehicle manufacturers. Thus, the financial-affordability test used previously by the DOT was replaced by net-benefit maximization, a reform that resulted in stricter standards than would have resulted if the DOT had taken into account the dismal financial condition of GM and Ford.

\section{The Rationale for Size-based Reform}

For model years 2008 through 2011, the DOT reformed the CAFE system so that the stringency of a manufacturer's CAFE standard was adjusted based on the size distribution of new vehicles in the company's fleet. Since it is generally easier to achieve good fuel economy in a small rather than a large vehicle, small vehicles were assigned tougher mpg targets than large ones.

The size-based reform had several policy advantages (DOT 2006). Fortunately, at least one of these advantages appealed to each of the main stakeholders.

First, reform reduced the safety concerns raised by NAS because any vehicle downsizing would cause the vehicle to be assigned a stricter mpg target. Instead of downsizing vehicles, which would save fuel by reducing vehicle weight, manufacturers were encouraged to comply by adopting innovative technology. Since the reform was based on a vehicle's dimensions (called "footprint" in the auto business), not weight per se, innovative light-weight materials remained a viable compliance strategy.

Second, the new size metric created a more level playing field for vehicle manufacturers. This was a critical issue to the UAW, GM, and Ford because Toyota and other competitors were beginning to challenge the dominance of Ford and GM in the market for large SUVs and pick up trucks. And in previous years, Toyota had accumulated large amounts of CAFE credits by competing only in the market for smaller SUVs. In other words, if GM and Ford can survive their near-term financial troubles, there is no reason to believe that the size-based CAFE standards for model years 2008 to 2011 will place them at a long-term competitive disadvantage.

Third, the smallest SUVs were subjected to roughly the same mpg targets as large passenger cars. No longer did the designation "light truck" provide more lenient regulatory treatment than the "car" designation. As a result, there was no perverse regulatory incentive for companies to offer SUVs or minivans instead of large sedans or station wagons. And there was no perverse incentive to raise the ground clearance of a vehicle, possibly creating rollover risks, in order to achieve the "light truck" classification.

Finally, reform saved more fuel because all vehicle manufacturers were induced to innovate. Moreover, the scope of the program was expanded to include large passenger SUVs (e.g., the Hummer) that had previously been exempt from mpg standards. The DOT considered the possibility that the size-based formula might encourage companies to offer larger vehicles, but this outcome seemed unlikely due to the cost of larger vehicle platforms and the growing consumer interest in car-like SUVs. 


\section{An Appeal to the President}

In 2005 there was some last-minute second guessing about CAFE reform. As fuel prices ran over $\$ 3.00$ per gallon for a brief period and the red ink in Detroit mushroomed, some White House staffers got cold feet about tighter CAFE standards.

The dissenters advocated a return to the CAFE "freeze" of the 1990s based on two arguments. First, "we don't need CAFE anymore," they argued, because high prices at the pump will spur plenty of conservation. Proponents of CAFE reform responded that longterm market prices will not fully account for concerns about energy and national security, the risks of climate change, and possible irrationalities in how consumers weigh fuel savings in purchasing decisions. Second, dissenters argued that tighter CAFE standards might force GM and Ford into Chapter 11 bankruptcy. Proponents of CAFE reform responded that the stringency of CAFE standards should be set based on net benefits, not the financial fortunes of specific companies, especially since the new sized-based structure provided a level playing field for each manufacturer offering a vehicle of a specific size.

The policy debate was waged in the Oval Office in early 2005. President Bush decided to stay with CAFE reform. Indeed, in his 2007 State of the Union message, President Bush called for even stricter mileage standards for both cars and light trucks over the next ten years under a size-based CAFE program informed by benefit-cost analysis.

\section{A Wedge between Consumers and Producers?}

The OIRA and the CEA shared a concern that tighter CAFE standards could cause vehicle producers to build vehicles that consumers do not wish to purchase, especially if fuel prices decline more than expected in the years ahead. Since fuel taxes are not likely to be increased, there is a danger that federal regulation will drive a wedge between what consumers want to purchase and what vehicle makers are required to produce under CAFE. The DOT analysis did not account for the utility losses to consumers who might prefer even larger engines, more interior volume, and other fuel-consuming comforts.

As the OIRA and the DOT were completing the CAFE reform proposal in 2005, Congress finally passed consumer tax credits for fuel-efficient vehicles in the comprehensive energy bill. Scheduled to take effect January 1,2006, the scope of the credits was expanded at our request to include advanced diesel technology as well as hybrids and fuel cells. Although consumer tax credits are far from a perfect response to the potential "wedge," they may stimulate both consumers and producers to have more interest in fuel-saving innovation than would otherwise be the case.

Thus, the portfolio of policies that the OIRA sought is now operating on both the demand and supply side of the market for fuel economy. The recent advances in hybrid engines and advanced diesel technology announced by Honda, Toyota, Ford, GM, Daimler-Chrysler, and BMW have been encouraging. As more experience with these policies accumulates, adjustments may need to be made in response to economic realities.

\section{Reducing Air Pollution from Coal Plants}

One of President Bush's unsuccessful legislative proposals, the Clear Skies Initiative, was an ambitious program to replace numerous federal and state clean-air programs with a 
national "cap-and-trade" program covering the electric utility industry. The idea was to place a cap on total industry emissions of sulfur dioxide, nitrogen dioxide, and mercury but to allow plants to trade emissions credits in order to keep the cost of the program as low as possible, just as had been done in the successful 1990 program to combat acid rain (Stavins 1998). The OIRA assisted the EPA in preparing the benefit-cost analysis for Clear Skies, which called for a 70 percent reduction in the three pollutants over the next fifteen years.

Clear Skies did not move in Congress because it became embroiled in a political dispute about what should be done about the threat of global warming and the possibility of mercury "hot spots" (Vendantam 2005). As the prospects for passage of Clear Skies dwindled, the White House asked the OIRA to work with the EPA on regulations under existing authority to reduce coal plant air pollution.

As a result, two coordinated rule makings were issued in 2005: the Clean Air Interstate Rule (CAIR), which places caps on sulfur dioxide and nitrogen dioxide emissions, and the Clean Air Mercury Rule (CAMR), which places caps on mercury emissions. The caps on sulfur and nitrogen emissions were designed to help states and local communities meet health-based air standards for ozone and particulates. Without passage of Clear Skies, those caps could be applied only in states east of the Mississippi, where long-range transport of coal plant pollution was significant. The fifty-state mercury program was grounded in a rarely-used provision of the 1970 Clean Air Act, even though litigation against this creative use of existing authority was expected.

As a package, the two rule makings were quite costly to businesses and consumers: CAIR was projected to cost almost $\$ 2$ billion per year, while the controls on mercury were projected to cost an additional $\$ 750$ million per year by 2020 (EPA 2005a,b). The cost of both rules was minimized by the creation of trading markets, where plants facing high costs of control could purchase emissions credits from plants facing low costs of control.

Surprisingly, the benefit-cost case is far weaker for CAMR than for CAIR, even though CAIR is far more costly. This is because the evidence of benefits from mercury removal is quite weak. As a result, the OIRA exerted a proregulation role on CAIR but worked hard to reduce the unnecessary economic burdens that otherwise might have been imposed by CAMR.

\section{CAIR}

In regions of the country that do not meet the EPA's health-based air quality standards, it is often impossible to achieve healthy air without greater emissions reductions by sources in upwind states. Using the Clean Air Act's "good neighbor” authority, EPA was empowered to prevent one state from causing air quality problems in a downwind state.

A regional cap-and-trade program for sulfur dioxide and nitrogen dioxide was established for twenty-eight states and the District of Columbia. Under CAIR, overall emissions from power plants in the region were capped to ensure a 50 percent emission reduction by 2009-2010 and a 65-70 percent reduction by 2015 (EPA 2005a).

The public health benefits of CAIR are estimated to be impressive (EPA 2005a). By 2015, the reductions in particle concentrations (due largely to the sulfur controls) are projected to prevent 17,000 premature deaths, 8,700 cases of chronic bronchitis, 22,000 nonfatal heart attacks, 10,500 hospitalizations, 1.7 million lost workdays and 9.9 million days of 
restricted physical activity. The health benefits from diminished ozone (smog) levels (due to nitrogen controls) are less impressive but still substantial: 2,800 fewer hospital admissions for respiratory illnesses, 280 fewer emergency room visits for asthma, 690,000 fewer days with restricted activity, and 510,000 fewer days where children are absent from school due to illnesses. The number of premature deaths prevented by the nitrogen controls could be as large as 500 per year.

When expressed in monetary units, the total benefits of the overall CAIR rule were estimated to eventually exceed $\$ 150$ billion per year. The lion's share of these benefits is attributable to the premature deaths prevented by the sulfur controls. Thus the overall ratio of CAIR's benefits to costs was on the order of 75:1.

The OIRA was skeptical of some of these figures. In 2002 we asked the EPA to perform an alternative analysis with a series of less optimistic assumptions. The results were still encouraging. The alternative benefit estimate was a factor of ten smaller than the EPA's preferred estimate, but the benefit-cost ratio of CAIR remained favorable.

The OIRA worked with EPA analysts to take a closer look at the incremental benefits and costs of controlling sulfur and nitrogen. That inquiry suggested that sulfur emissions reductions beyond 70 percent would be defensible on benefit-cost grounds. Indeed, the OIRA had made the case - unsuccessfully — that the sulfur cap under Clear Skies should be tighter than what was proposed. The benefit-cost case for additional controls on nitrogen dioxide (beyond a 70 percent reduction) was far less clear.

The lawyers on the interagency team argued that the 2015 sulfur cap could not be set more stringently than a 70 percent reduction - even though it made good economic sense to do so-without exposing the rule to legal risk. Reductions larger than 70 percent could not be easily justified in court because additional reductions were not necessary to assist downwind states in achieving the EPA's standard of healthy air. However, as EPA tightens the twenty-four-hour air-quality standard for particulates, a tighter sulfur cap may become legally defensible in the years ahead (Eilperin 2006).

The OIRA also urged EPA to include industrial as well as utility sources of sulfur and nitrogen dioxide in a broader cap-and-trade program or in a tailored trading market for industrial sources. Although there was substantial interest in this suggestion, the poor financial condition of the manufacturing sector of the U.S. economy proved to be a formidable obstacle.

\section{CAMR}

At the same time that the OIRA was urging the EPA to make CAIR as stringent as possible, the OIRA was working hard to make sure that the CAMR rule was not overly stringent. The OIRA was also working against those who believed that no federal mercury rule was necessary.

\section{Mercury in the environment}

After mercury is emitted from the stack and deposited (e.g., during periods of rainfall), it is converted into a more toxic form (methyl mercury) and finds its way into water bodies. EPA scientists were concerned that people living near power plants might experience health risks from eating large amounts of locally caught fish contaminated with mercury. 
The most sensitive individuals are pregnant women because of the neurotoxic effects of methyl mercury on the rapidly growing brain of the fetus. In the 1990s, many states adopted fish advisories aimed at discouraging pregnant women from ingesting fish that might be contaminated with mercury. Unfortunately, fish advisories are often ignored, sometimes because low-income, subsistence populations rely on locally caught fish for their daily diet.

About 4-8 percent of pregnant women in the United States have been shown to have mercury levels in their blood that exceed the EPA's safe concentration, the reference level set to protect the fetus and small child (EPA 2005b). Surveys show that these women consume predominantly marine fish. However, there is no evidence that emissions from U.S. power plants are responsible for the elevated mercury levels in marine fish.

The initial thinking at the EPA was that strict mercury controls were necessary at every power plant to ensure that pregnant women living near plants were protected. If an 80-90 percent reduction in mercury emissions had been required at each plant, the cost could have been several billion dollars per year (Gayer and Hahn 2005). Indeed, the engineers from the DOE and the EPA were disputing whether such reductions were even technically feasible (especially for boilers that burn sub-bituminous and lignite coals). The OIRA and the EPA looked hard for a more cost-effective policy alternative.

A promising insight arose from environmental science: The nonelemental forms of mercury (e.g., oxidized and particulate mercury) are most likely to be deposited near plants, while the elemental form - the pure gas - enters the global pool of mercury and can be deposited virtually anywhere in the world. It is very difficult and expensive to control elemental mercury. Some plant-specific controls may be needed to address nonelemental mercury emissions, but a cap-and-trade program is most appropriate for pollutants (such as elemental mercury) that are rapidly dispersed and transported long distances.

\section{Reducing mercury emissions}

In the course of the rule making, the EPA and the OIRA discovered that CAIR by itself (i.e., without CAMR) was quite effective in reducing mercury (EPA 2005b) because the same controls used by utilities to reduce sulfur and nitrogen also reduce (nonelemental) mercury. Without CAIR or CAMR, the EPA projected forty-five to forty-seven tons per year of mercury emissions by 2020. CAIR alone was projected to reduce mercury emissions to thirty-four tons by 2020. Thus, at no extra cost, the CAIR rule was projected to cut overall mercury emissions by 26 percent. More importantly, emissions of nonelemental mercury, which tend to deposit locally, were projected to decline by 55 percent (from twenty-two to ten tons per year by 2020) due to CAIR alone.

The EPA's health risk assessment did not demonstrate any significant health risk from 10 tons per year of nonelemental mercury emissions, even among pregnant women who did not follow fish advisories. It is theoretically possible that some risks remained at a small number of plants with unusual conditions, since the EPA models were regional in coverage and did not have fine precision very close to plants. However, under CAMR, rare instances of localized risk can be addressed by state and local regulators.

The EPA and the OIRA ultimately agreed that the case for strict controls at every plant was weak, especially after the effects of CAIR were considered. The policy debate then shifted to 
whether the United States should make a significant economic investment, beyond CAIR, to further reduce our nation's contribution to the global pool of mercury.

U.S. power plants contribute to the global mercury pool, but the best estimate is that the contribution in recent years was less than 5 percent of the global total (EPA 2005a). Nevertheless, the United States has an interest in stimulating the development of new mercury control technologies that might be used worldwide to reduce the global pool. Based on this rationale, which was outside a traditional benefit-cost framework, the OIRA supported a national cap-and-trade program to reduce the mercury emissions expected to remain after CAIR. The end result is that in 2020, CAMR sets a cap on national mercury emissions from power plants at sixteen tons per year, about a 65 percent reduction from pre-CAIR levels and a 53 percent reduction from post-CAIR levels.

Although the 2020 mercury cap costs about $\$ 750$ million per year beyond CAIR, it has several qualitative benefits. It stimulates U.S. industry to develop new mercury-control technologies that can reduce emissions of elemental mercury. As new technologies are commercialized, they can be used throughout the world as well as in the United States. As CAMR reduces further the U.S. contribution to the global mercury pool, other countries may be more readily persuaded that they should reduce their contributions to the global pool. CAMR also makes a contribution to reducing nonelemental mercury emissions (from ten to seven tons per year). The combination of CAIR and CAMR reduces nonelemental mercury emissions by 68 percent, providing an extra measure of assurance that pregnant women living downwind of power plants are protected. Although this benefit could not be quantified, CAMR was considered a precautionary investment with a plausible fairness rationale.

\section{Objections to emissions trading}

Some commentators object to the idea of allowing power plants to trade mercury allowances (Heinzerling and Steinzor 2004). They argue that "hot spots" may result near plants where owners decide to buy allowances rather than spend capital to control mercury. Of course, this concern is valid only if pregnant women happen to live downwind at points of high deposition where large amounts of locally caught fish are ingested regularly.

OIRA and EPA economists argued that market forces are likely to reduce rather than increase any "hot spots" that now exist. Economies of scale in pollution control are greatest at the largest plants, those that emit the most mercury and have the most local mercury deposition. If the average plant reduces mercury emissions by 70 percent, even larger percentage reductions will occur at the large power plants. Moreover, the permission to trade is likely to cause disproportionate reductions in nonelemental mercury, which is easier and cheaper to control than elemental mercury. If for some unexpected reason "hot spots" do occur at some plants, state and local authorities have adequate authority to set more stringent standards for those plants. In fact, some states are already setting standards that are more stringent than CAMR (Adams 2006).

In the final analysis, the $\$ 750$ million annual cost of the CAMR rule was supported by the OIRA and the EPA on the basis of qualitative benefits that could not be monetized. The rule should certainly be revisited as more is understood about the benefits and costs of controlling mercury. Some analysts believe a more stringent rule may be supportable by 
new science indicating mercury intake is related to elevated risks of heart attacks among adults (Rice and Hammitt 2005). The rule may have to be revisited sooner rather than later if it does not survive the barrage of litigation that has been launched against it.

\section{Taking Stock of the OIRA's Proregulation History}

The OIRA's proactive stances on trans fats, diesel engine exhaust, vehicle fuel economy, and coal plant pollution were unusual by historic standards. The early years of the OIRA's history were dominated by efforts to reduce regulatory burdens on industry (Morrison 1986; Percival 1991). Yet the OIRA's support of sound rules in the 2001-2006 period was certainly not unprecedented.

In fact, the OIRA's role in diesel exhaust control is reminiscent of the accelerated phase-out of leaded gasoline that occurred early in the Reagan Administration. In that case, industry came to President Reagan's "regulatory relief" task force seeking a delay of the ban on leaded gasoline that President Carter's EPA had issued. Instead the Reagan OIRA was ultimately persuaded to sign on to the opposite course: an acceleration of the lead phase-out. The pivotal input was a careful benefit-cost analysis by EPA analysts, including review and support by the OIRA (McGarity 1991; Gray et al. 1997; Morgenstern and Landy 1997).

In the Clinton years, the OIRA also made important proregulation accomplishments. For example, the OIRA effectively resisted a determined effort by the DOT to weaken the automobile airbag requirement. In the face of public outcry from libertarians and citizens who feared the explosive device, DOT sought the OIRA approval for a modified rule that would have placed a manual on-off switch in every new vehicle produced with an airbag. The OIRA blocked this proposal on the grounds that the safety harms from a misused on-off switch might be vastly greater than the benefits. Once drivers and front-seat passengers were informed about the benefits and risks of airbags and safety belts through a massive education effort, public acceptance of the technology improved considerably (Graham 2001).

What was different about the OIRA in the George W. Bush years was the OIRA's proactive role in the priority-setting process. In addition to serving as an end-of-thepipeline mechanism for quality control, the OIRA became a determined participant in the formulation stage of policy making.

The OIRA's proregulation accomplishments in the 2001-2006 period also underscore a lesson that has been repeated throughout the OIRA's twenty-five-year history: Careful economic analysis sometimes suggests that more federal regulation is a wiser public policy than less federal regulation (Smith 1984; Mendeloff 1988; McGarity 1991; Breyer 1993; Sunstein 2002). Regardless of whether the OIRA is working in a conservative or liberal administration, this is an essential feature of "smart regulation" based on science and economics.

The diesel exhaust and coal plant rule makings also highlight why it is important for the OIRA to be capable of scrutinizing claims of benefits as well as costs. In retrospect, one of my best personnel moves at the OIRA was to recruit the office's first toxicologist and epidemiologist, in addition to new specialists in engineering and health policy. The new experts joined the OIRA's economists and statisticians as the office began to delve more deeply into the technical aspects of regulatory benefit estimates (OMB 2002). Although we 
respected the views of agency experts, we began to ask more penetrating questions about how benefits were determined.

In the diesel exhaust rule making, we did not accept at face value the huge benefit estimates prepared by the EPA in collaboration with their science advisors. We recognized that there was considerable imprecision (and possible bias) in the EPA estimates, and thus instructed the EPA to prepare an alternative benefit analysis based on more pessimistic assumptions. When we learned that even the alternative benefit estimates supported the EPA's policy, we became even more determined advocates of the EPA's position in the White House.

The benefit story was much more complex for pollution from coal plants. After persistent probing of the EPA over several years, we became convinced that tighter controls on sulfur emissions promised much greater benefits than tighter controls on mercury emissions, even though the mass media and some activist groups often portrayed mercury as the worst of all pollutants. The position we advocated needs to be reevaluated in the years ahead as more scientific knowledge is obtained about both sulfur and mercury emissions from coal plants.

The CAFE rule making illustrates why it is important for the OIRA analysts to remain engaged on an important issue, even if the "first-best" policy is rejected. In the George W. Bush administration and in Congress, higher fuel taxes or new carbon taxes were dead on arrival, even though some economists in the administration saw them as the best course for public policy.

Rather than give up on energy conservation, the OIRA worked persistently with multiple agencies, including the CEA, to improve federal fuel economy regulation and create consumer tax credits for purchase of vehicles with innovative fuel-saving technologies. Coupled with the sustained rise of fuel prices, these "second-best" policies appear to be

stimulating a market dynamic in favor of more hybrid engines, more advanced diesel technology, and more lightweight construction materials. The resulting technological innovations provide a solid foundation for more ambitious national or international policies to promote energy security and slow the pace of climate change.

\section{Conclusions and Future Directions for Research}

Each year, the OMB publishes agency estimates of regulatory costs and benefits. These data show that during my tenure as the OIRA administrator, the overall net benefits from regulation were larger than was experienced in the 1990s (see Table 1). In part, this occurred because we cut the growth rate of costly major rules by 49 percent compared to the 1990s (OMB 2004, 2005, 2007a,b). But we also encouraged rule making with impressive benefits, causing average yearly benefits from major rules to increase 108 percent compared to the 1990s (OMB 2007a,b).

Overall, the quantified net benefit of major rules from 2001 to 2006 increased by 262 percent compared to the 1990s (OMB 2007b). Fewer major rules were issued, but those that were issued had superior benefit-cost justifications. One of the key lessons is that we should judge regulators not by the number of rules they issue but by their overall contribution to social welfare (Sunstein 2002; Adler and Posner 2006).

Reviewing major new rules was a big challenge, but modernizing the sea of existing federal regulations was an even bigger chore (Crain 2005). Since the OMB began to keep records in 1981, an additional 20,000 new federal rules have been adopted (OMB 2007). For the 
vast majority of these rules, the regulator has never looked back to determine what the rule accomplished or how expensive it was. Thus at the same time that the OIRA worked to enhance the efficiency of new rules, we also instructed regulators to reexamine and streamline about 100 existing regulations, the first serious "look-back" effort since the early Reagan years (OMB 2003, 2004, 2007).

What surprised some, however, was how frequently our office made a proregulation argument to regulators, to White House staff, to the vice president's office, and even to the president himself. Before coming to government, I had discovered that public health regulators suffer from a syndrome of paranoia and neglect: excessive regulation of some risks, inadequate regulation of others (Graham 1997). Past practice at the OIRA had focused on the first part of this problem, but the OIRA had not yet begun to tackle the second part, a longstanding concern of progressive regulatory scholars (Breyer 1993; Sunstein 2002; Bagley and Revesz 2006). I am pleased to have begun an effort at the OIRA to address this imbalance.

Unfortunately, the benefit-cost framework for regulatory reform is only as powerful as the tools and data available to implement the framework. Based on my five years of experience overseeing federal regulatory agencies, I have become even more convinced than I was previously of the need for our nation to make expanded research investments in regulatory economics, science, and engineering. The information base on which we made multibillion-dollar decisions was often remarkably slim. Hence, I conclude this article with several examples of the urgent need for research.

First, environmental regulators assume that each statistical life extended by reducing air pollution should be valued at $\$ 6$ million (EPA 2004, 2005a). This figure was a crucial input to the benefit assessments for both the diesel engine and coal plant rule making. Upon close inspection, the figures used in the benefit assessments were based primarily on the

Table I Total net benefits from major federal rules, 1992-2005 (in billions of 200। dollars)

\begin{tabular}{cccc}
\hline Year & Benefits & Costs & Net benefits \\
\hline 1992 & 81.1 & 16.3 & 64.8 \\
1993 & 7.7 & 8.1 & -0.4 \\
1994 & 11.4 & 8.7 & 2.7 \\
1995 & 3.1 & 3.5 & -0.4 \\
1996 & 19.6 & 2.6 & 17.0 \\
1997 & 2.5 & 2.4 & 0.1 \\
1998 & 12.8 & 5.4 & 7.4 \\
1999 & 15.9 & 8.4 & 7.5 \\
2000 & 35.1 & 17.9 & 17.2 \\
2001 & 0.0 & -4.8 & 4.8 \\
2002 & 4.3 & 1.9 & 2.4 \\
2003 & 3.1 & 2.5 & 0.6 \\
2004 & 52.2 & 6.8 & 45.4 \\
2005 & 74.0 & 5.6 & 68.4 \\
2006 & 26.0 & 2.5 & 23.5 \\
\hline
\end{tabular}

Notes: Figures for 1992 and 2000 include rules issued prior to the presidential inauguration in the next year. Based on 134 major federal rules where agencies produced estimates of benefits and costs. All figures are annualized. Sources: OMB 2007a,b. 
wage premiums that are necessary to attract workers into occupations with elevated risks of traumatic injury (Viscusi and Aldy, 2003). Although environmental economists use the phrase "benefit transfer" to describe this form of extrapolation, it would be more useful if regulatory analysts had some relevant data on the public's economic demand for improved air quality. That is a challenging research question but one that would be very worthwhile to study directly with innovative research designs and hard data.

Second, the estimated air-quality benefits are based on another crucial assumption: that all fine particles are equally toxic, regardless of their size or chemical composition. Yet there are sound toxicological reasons to suspect that sulfates, nitrates, and carboncontaining particles vary considerably in their toxicity at low concentrations. Moreover, the epidemiologic evidence that currently links air pollution and adverse health outcomes has progressed only modestly beyond what Lester Lave and colleagues published in the early 1970s (Lave and Seskin 1970). Much of the recent literature does not make use of the modern econometric tools that are now considered standard in economics. I would like to see the next generation of environmental epidemiology studies be produced by teams of analysts that include physicians, toxicologists, environmental scientists, statisticians, and econometricians. The future stakes in regulatory policy - whether measured in public health or monetary terms - justify new kinds of scientific collaborations.

Finally, we need better economic models of how consumers and producers in the automotive industry will respond to a multiplicity of federal and state regulations, higher fuel prices, tax policies, and a major restructuring of the industry. A key question is what products will arise from a U.S. automotive market with fuel prices below European experience ( $\$ 4-5$ per gallon) but considerably above the U.S. experience of the 1990s ( $\$ 1-2$ per gallon). As energy security and climate change concerns intensify over the next decade, there will be numerous policy proposals aimed at the world transport sector. Unless our economic models of the global auto industry improve considerably, much of this policymaking will be based on guesswork. I believe our universities, think tanks, and government policy shops are capable of producing a stronger analytic foundation for future policy making.

\section{References}

Adams, Rebecca. 2006. State dropout rate high for Bush mercury plan. Congressional Quarterly Weekly Report May 29: 1456-57.

Adler, Matthew D., and Eric A. Posner. 2006. New foundations of cost-benefit analysis. Cambridge, MA: Harvard University Press.

Andrews, Richard N. L. 1984. "Economics and Environmental Decisions, Past and Present." In Economics and environmental decisions: past and present. environmental policy under, Reagan's executive order: The role of benefit-cost analysis, ed. V. Kerry Smith, 43-85. Chapel Hill: University of North Carolina Press.

Bagley, Nicholas, and Richard L. Revesz. 2006. Centralized oversight of the regulatory state.
Washington, DC: AEI Joint Center on Regulatory Studies, Related Publication 6-12.

Blumstein, James. 2001. Presidential administration and administrative law: Regulatory review by the executive office of the president: An overview and policy analysis of recent issues. Duke Law Journal 51: 851.

Breyer, Stephen. 1993. Breaking the vicious circle: Toward effective risk regulation. Cambridge, MA: Harvard University Press.

Crain, W. Mark. 2005. The impact of regulatory costs on small firms. Washington, DC: U.S. Small Business Administration.

Eilperin, Juliet. 2006. EPA cuts soot level allowable daily in air. Washington Post Sept 26: A3. 
Energy Information Administration. 2005. Annual Energy Outlook.

Gayer, Ted., and Robert Hahn. 2005. The political economy of mercury regulation. Regulation 28 , no. no. 2: 26-33.

General Accountability Office. 2003. OMB's role in reviews of agencies' draft rules and the transparency of those reviews. Washington, DC: General Accountability Office.

Graham, John D. 1997. Legislative approaches to achieving more protection against risk at less cost, 13-58. Chicago, IL: University of Chicago Legal Forum.

Graham, John D. 2001. Technological danger without stigma: the case of automobile airbags. In Risk, media and stigma, ed. James Flynn, Paul Slovic, and Howard Kunreuther, 241-56. London: Earthscan.

Graham, John D., and Jonathan B. Wiener, eds. 1995. Risk versus risk: tradeoffs in protecting health and the environment. Cambridge, MA: Harvard University Press.

Graham, John D., Paul R. Noe, and Elizabeth L. Branch. 2006. Managing the regulatory state: The experience of the bush administration. Fordham Urban Law Journal 33, no. no. 4: 953-1002.

Gray, George M., Laury Salisman, and John D. Graham. 1997. The demise of lead in gasoline. In The Greening of Industry, ed. John D. Graham and Jennifer Kassalow. Cambridge, MA: Harvard University Press.

Hahn, Robert W., and Cass R. Sunstein. 2002. A new executive order for improving federal regulation? Deeper and wider cost-benefit analysis. University of Pennsylvania Law Review 150: 1489.

Heinzerling, Lisa, and Rena I. Steinzor. 2004. A perfect storm: Mercury and the Bush administration, Part II. Environment Law Reporter 34: 10485-496.

Kagan, Elena. 2001. Presidential administration. Harvard Law Review 114: 2245.

Lave, Lester, and Eugene Seskin. 1970. Air pollution and human health. Science August 21: 723-33.

McGarity, Thomas O. 1991. Reinventing rationality: the role of regulatory analysis in the federal bureaucracy. New York: Cambridge University Press.

1998. A cost-benefit state. Administrative Law Review 50: 7-79.

Mendeloff, J. 1988. The dilemma of toxic substance regulation: How overregulation causes underregulation at OSHA. Cambridge, MA: MIT Press.

Moe, Terry M, and Scott A. Wilson. 1994.

Regulating regulation: The political economy of administrative procedures and regulatory instruments. Law and Contemporary Problems Spring: 1-44.

Morgenstern, R. D., and M. K. Landy. 1997. Economic analysis: benefits, costs, implications. Washington, DC: Resources for the Future.

Morrison, Alan B. 1986. OMB interference with agency rulemaking: the wrong way to write a regulation. Harvard Law Review 99: 1059.

National Academy of Sciences. 2002. Effectiveness and impact of corporate average fuel economy standards. Washington, DC.

Percival, Robert V. 1991. Checks without balance: executive office oversight of the environmental protection agency. Law and Contemporary Problems Autumn: 127-204.

Power, Stephen, and Jacob M. Schlesinger. 2002. Bush's rules czar brings long knife to new regulations. Wall Street Journal June 12: 1.

Rice, Glenn, and James K. Hammitt. 2005.

Economic Valuation of Human Health Benefits of Controlling Mercury Emissions from U.S. Coal-Fired Power Plants. Northeast States for Coordinated Air Use Management.

Schroeder, Christopher H. 1986. Rights against risk. Columbia Law Review 86,, no. no. 3: 495-562.

Smith, V. Kerry, ed. 1984. Environmental policy under Reagan's executive order: The role of benefit-cost analysis. Chapel Hill: University of North Carolina Press.

Stavins, Robert N. 1998. What can we learn from the grand policy experiment? Lessons from $\mathrm{SO}_{2}$ allowance trading. Journal of Economic Perspectives 12, no. no. 3: 69-88.

Sunstein, Cass R. 2002. Risk and reason: Safety, law and the environment. New York: Cambridge University Press.

U.S. Congress. Senate. 2001. Committee on Governmental Affairs. Nominations of Angela B. Styles, Stephen A. Perry, and John D. Graham. 107th Congress, 1st Session. May 17.

U.S. Department of Transportation. 2003. Light truck fuel economy standards for model years 2005-2007. Federal Register 68: 16868.

- 2006. Average fuel economy standards for light trucks: Model years 2008-2011. Federal Register 71: 17566. 
U.S. Environmental Protection Agency. 2002. Final technical support document: Nonconformance penalties for 2004 highway heavy duty diesel engines. Washington, DC: U.S. Environmental Protection Agency.

2004. Control of emissions of air pollution from nonroad diesel engines and fuel. Federal Register 69: 38958.

.2005a. Rule to reduce interstate transport of fine particulate matter and ozone (Clean Air Interstate Rule). Federal Register 70, no. 91: 25162-25227.

2005b. Revision of the December 2000 regulatory finding on the emissions of hazardous air pollutants from electric utility steam generating units and the removal of coal- and oil-fired electric utility steam generating units from the section 112(c) list; final rule. Federal Register 70, no. 59: 15994.

2006. Light-Duty Automotive Technology and Fuel Economy Trends: 1975 through 2006. EPA420-R-011.

U.S. Food and Drug Administration. 2003. Trans fatty acids in nutrition labeling, nutrient content claims, and health claims. Federal Register 68: 41,434 .

U.S. Office of Management and Budget. 2001. Making sense of regulation. Washington, DC: U.S. Office of Management and Budget.

2002. Stimulating smarter regulation.

Washington, DC: U.S. Office of Management and Budget.
2003. Informing regulatory decisions. Washington, DC: U.S. Office of Management and Budget.

2004. Progress in regulatory reform. Washington, DC: U.S. Office of Management and Budget.

2005. Validating regulatory analysis.

Washington, DC: U.S. Office of Management and Budget.

2007a. 2006 report to congress on the costs and benefits of federal regulations. Washington, DC: U.S. Office of Management and Budget.

2007b. Draft 2007 report to congress on the costs and benefits of federal regulations. Washington, DC: U.S. Office of Management and Budget.

Vendantam, Shankar. 2005. Senate impasse stops "Clear Skies" measure. Washington Post March 10: A4.

Viscusi, W. Kip, and Joseph E. Aldy. 2003. The value of statistical life: A critical review of market estimates throughout the world. Journal of Risk and Uncertainty 27,, no. no. 1: 5-76.

West, William F. 2005. The institutionalization of regulatory review: Organizational stability and responsive competence at OIRA. Presidential Studies Quarterly 35: 76.

White House. 2001. National energy policy. Report of the National Energy Policy Development Group. 